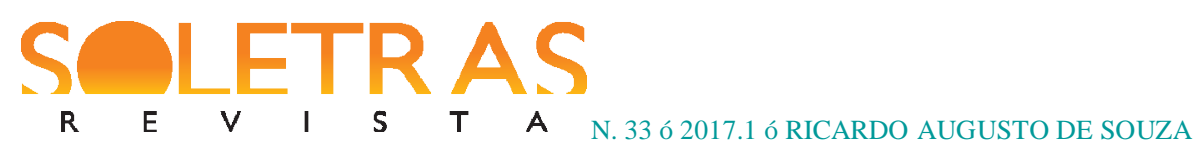

\title{
Entrevista
}

\section{Laboratório de Psicolinguística da FALE}

\author{
Ricardo Augusto de Souza ${ }^{1}$ \\ Universidade Federal de Minas Gerais
}

\section{Entrevista concedida aos professores Kátia Abreu e Eduardo Kenedy}

Soletras: Quando o seu LAB foi fundado? Qual foi sua experiência em LABs de Psicolinguística anterior à fundação do LAB que coordena?

O Laboratório de Psicolinguística da Faculdade de Letras da UFMG foi oficialmente inaugurado em 2011. Refiro-me a inauguração oficial como o estabelecimento de um espaço físico, no prédio da Faculdade, efetivamente dedicado às atividades do Laboratório. Este espaço físico é constituído por duas salas: uma sala onde se encontram nossos equipamentos para a condução de experimentos; um anexo onde temos uma sala de reuniões, computadores em estações de trabalho que podem ser utilizados por todos os membros e estudantes do laboratório e uma área reservada que funciona como gabinete da fundadora do laboratório, a Professora Maria Luiza Cunha Lima.

Mas as atividades de pesquisa que levaram à inauguração de nosso laboratório foram iniciadas cerca de dois anos antes, com o estabelecimento, junto Área de Concentração em Linguística Teórica e Descritiva do Programa de Pós-Graduação em Estudos Linguísticos da Faculdade de Letras da UFMG, da Linha de Pesquisa em Processamento da Linguagem.

Soletras: Quais os principais temas de pesquisa que seu LAB vem contemplando ao longo dos anos?

No nosso Laboratório tem havido dois temas prevalentes: o processamento de correferência anafórica, e interações de representações de línguas específicas processamento sentencial bilíngue. Mais recentemente, temos tido uma frente crescente de estudos com foco em marcadores cognitivos, comportamentais e experienciais de proficiência e dominância em L2. E especialmente em virtude do ingresso de novos pesquisadores no Lab, estamos

\footnotetext{
${ }^{1}$ Professor Associado de Língua Inglesa e docente do Programa de Pós-Graduação em Estudos Linguísticos da UFMG. ricsouza.ufmg@gmail.com
} 


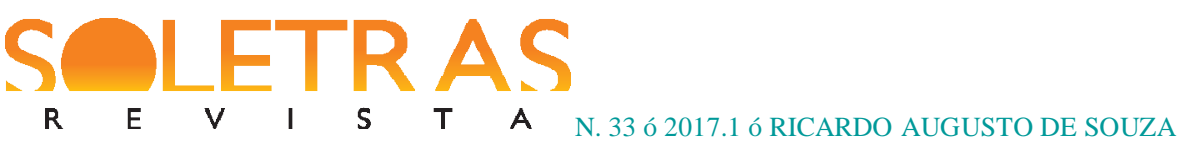

implementando também estudos sobre a aquisição e o processamento de morfologia flexional em L2, estudos sobre a produção linguística com base em Gramática de Construções, e estudos sobre processamento lexical em L2.

Soletras: Quais as principais técnicas experimentais que vêm sendo empregadas nas pesquisas de seu Lab nos últimos anos?

Nosso laboratório tem equipamentos que permitem experimentos comportamentais, rastreamento ocular e com potenciais evocados por eventos (EEG). Além dessas técnicas, há interesse em técnicas de validação psicométrica, em resposta a demandas de alguns dos projetos de pesquisa desenvolvidos no laboratório.

Soletras: Você poderia fazer uma estimativa do total de pesquisas de mestrado e doutorado que foram conduzidas no Lab?

Doze dissertações de Mestrado e 14 teses de doutorado.

Soletras: O Lab integra alguma rede de cooperação? Poderia citar outros Labs parceiros?

Sempre buscamos interações com outros laboratórios e centros. Entre as colaborações que podemos citar, tivemos boa aproximação do LAPROL/UFPB, principalmente com a equipe supervisionada pelo Professor Márcio Martins Leitão. Tivemos interações produtivas também com a Professora Eva Fernández, do Queens College da CUNY, e com o Professor Amit Almot, da University of South Carolina, ambos nos Estados Unidos.

Soletras: Além de trabalhos teóricos de interesse para a área da Psicolinguística, seu Lab desenvolve também pesquisas de interface com a área da Saúde elou da Educação? Se sim, quais?

O foco primário de nosso trabalho até o presente momento no Laboratório tem sido em problemas teóricos. Assim, é correto dizer que até o presente nossa preocupação principal tem sido com o exercício de ciência básica.

Porém, como é grande a procura por nosso laboratório de pessoal com inserção no ensino de L2, em função dos estudos sobre o bilinguismo que desenvolvemos no Lab, há um grande potencial para que nossos estudos possam no mínimo informar o debate sobre questões aplicáveis ao ensino de línguas. 


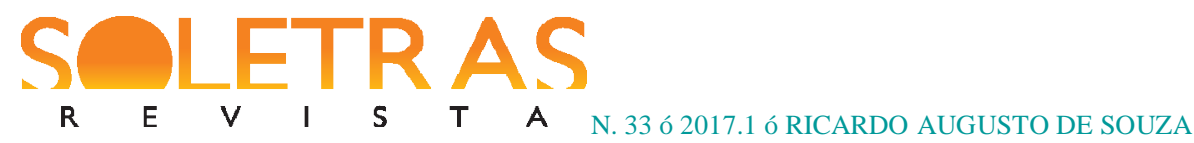

Além disso, um desdobramento claro dos trabalhos por nós desenvolvidos tem sido a investigação da validade de métricas obtidas por tarefas específicas, o que nos permite dizer que uma frente que pode se desdobrar de nossos estudos é a instrumentação psicométrica, sendo que nesta via percebemos um potencial de diálogo, por exemplo, com trabalhos no campo do diagnóstico neuropsicológico. Inclusive houve, em um momento anterior do Lab, uma colaboração específica com problemas de ordem clínica, especificamente questões relacionadas ao Transtorno do Déficit de Atenção com Hiperatividade.

Sobretudo, nosso laboratório tem plena abertura para o acolhimento a propostas que se encaixem em nossas frentes de pesquisa com um viés aplicado, seja à educação, à saúde, ou outras áreas onde questões de linguagem tenham proeminência.

Soletras: Deixe uma palavra de seu Lab para os leitores alunos de graduação interessados em ingressar na área da psicolinguística experimental.

Entendemos que a psicolinguística tem um papel de grande relevância para o desenvolvimento da Linguística como uma ciência empírica. Entendemos que o estudante interessado em psicolinguística deve ser também um estudioso interessado e plenamente aberto a colocar sob teste rigoroso a plausibilidade comportamental, e possivelmente neurofisiológica, de modelos descritivos sobre o funcionamento e a aquisição das línguas naturais. $\mathrm{O}$ estudante interessado em ingressar na psicolinguística experimental deverá estar aberto a fazer dialogar com franqueza os conhecimentos teóricos em Linguística com o conhecimento da psicologia cognitiva sobre os modos de funcionamento da mente humana, estando aberto para o questionamento incessante de ideias.

Entrevista realizada 22 de junho de 2017. 